UDC: $811.134 .2^{\prime} 42$

DOI: https://doi.org/10.18485/hispserb.2019.2.ch4

\author{
Dragana Bajić ${ }^{1}$ \\ Instituto Cervantes, Belgrado \\ Serbia
}

\title{
MARCADORES REFORMULATIVOS DE RECONSIDERACIÓN
}

\begin{abstract}
Resumen
En el marco de la pragmática lingüística, desde los mismos principios de la disciplina, ha suscitado especial interés el tema de los marcadores discursivos como uno de los factores de la coherencia discursiva por ser claves en el procesamiento de la información y en la transmisión de intenciones comunicativas del locutor. El estudio de estos elementos ha dado importantes resultados sobre todo en el seno de la hispanística. Por esta razón, apoyándonos más en el aparato teórico desarrollado por los hispanistas, elegimos la clase de los reformuladores de reconsideración para analizarlos contrastivamente con los del serbio. En el grupo se distinguen dos subgrupos: el de los marcadores que introducen una reformulación nueva (total, después de todo) y el de los que instruyen una reformulación definitiva (al fin y al cabo, a fin de cuentas, en definitiva, etc.). Teniendo en cuenta que toda reformulación establece cierto tipo de repetición, nuestro objetivo es examinar cómo y con qué medios lingüísticos se consigue esta relación, para después detectar cuáles son sus correspondientes en serbio. Los resultados obtenidos serán relevantes sobre todo en dos áreas de la lingüística aplicada: en la enseñanza del español y el serbio como lenguas extranjeras y en la actividad traductora.
\end{abstract}

Palabras clave: marcador discursivo, reformulación, reconsideración.

$\overline{{ }^{1} \text { dacabaj@gmail.com }}$ 


\section{Introducción}

El aparato teórico utilizado en este artículo pertenece a la lingüística pragmática. Nos apoyaremos primero en los logros de los filósofos de la lengua, sobre todo en Grice $(1969,1975)$ a quien se deben nociones como la ostensión, la inferencia y la implicatura. Su distinción ente la implicatura convencional y la conversacional dio paso a otra entre el 'significado' lingüísticamente dado y el 'sentido' contextualmente derivado.

Retomando sus ideas los cognitivistas Dan Sperber y Deirdre Wilson (1986) crearon su Teoría de la Pertinencia; ellos diferenciaron la "explicatura de nivel inferior" con contenido lingüísticamente codificado de la "explicatura de nivel superior" como enriquecimiento de este contenido.

En el seno del estructuralismo francés los lingüistas Anscombre y Ducrot (1994) desarrollaron la Teoría de la Argumentación que opera con el concepto de "fuerza argumentativa".

Otra dicotomía inspirada en la cognitivista separación entre las representaciones conceptuales o lógicas y el cálculo que se realiza con ellas se debe a Blakemore (1987) y atañe a los "significados conceptual y procedimental". Esta demarcación no subsiste de forma tajante debido al distinto grado de gramaticalización de los marcadores.

En cuanto a la reformulación, Camacho Adarve (2009: 14) subraya que "las repeticiones siempre incluyen modificaciones pragmáticas" y Bazanella (1996) llama la atención sobre la variedad de sus funciones (cognitiva, estilística, argumentativa, textual, conversacional, interaccional y étnica). Según la definición de Martín Zorraquino y Portolés (1999: 4121) y Portolés (2011: 105 y 141), "[l]os reformuladores son marcadores que presentan el miembro del discurso en el que se encuentran como nueva formulación de lo que se pretendió decir con un miembro anterior". El término "miembro discursivo" se debe a Portolés (2011: 40-41); es "la unidad lingüística mínima en la que se puede localizar un marcador [y] puede ser menor que un enunciado".

Finalmente, a partir de la última década del siglo pasado se dieron los enfoques contrastivos orientados a la traducción (Rossari 1990 y 1994, Fløttum 1994, Cuenca Ordiñana \& Bach Martorell 2007, Borreguero Zuloaga 2011, Garcés Gómez 2009). Nuestro análisis se centrará en los sentidos contextualmente obtenidos de los reformuladores de reconsideración y de sus capacidades conmutativas, es decir, de las (im) posibilidades de sustituir un marcador con otro del mismo grupo en un determinado contexto. 


\section{Marcadores reformulativos de reconsideración}

Los marcadores de reconsideración son un subconjunto de los recapitulativos que Garcés Gómez (2008 y 2010) aisló tomando en cuenta la intención del hablante de expresar un punto de vista modificado que no necesariamente tiene que ser solo un resumen o una conclusión. Después de haber considerado otras posibilidades, expresadas o implícitas, el locutor formula una nueva percepción de la situación, una explicatura de nivel superior.

A continuación, la autora sigue distinguiendo los marcadores que introducen una opinión definitiva de los que exponen una nueva basada en el contenido precedente global. La siguiente tabla ilustra la lista de estos marcadores (las correspondencias entre serbio y español no son necesariamente horizontales):

\begin{tabular}{|c|c|c|c|}
\hline \multicolumn{4}{|c|}{ Marcadores de reconsideración } \\
\hline Marcadores de reformulación definitiva & Marcadores de reformulación nueva \\
\hline español & serbio & español & serbio \\
\hline $\begin{array}{c}\text { al fin y al cabo } \\
\text { a fin de cuentas } \\
\text { al fin y a la postre } \\
\text { en resumidas cuentas } \\
\text { en definitiva }\end{array}$ & $\begin{array}{c}\text { na kraju krajeva } \\
\text { u krajnjoj liniji } \\
\text { ukratkim crtama } \\
\text { konačno } \\
\text { dakle }\end{array}$ & $\begin{array}{c}\text { total } \\
\text { tospués de }\end{array}$ & $\begin{array}{c}\text { sve u svemu } \\
\text { posle svega } \\
\text { najzad, naposletku } \\
\text { konačno } \\
\text { (ipak) }\end{array}$ \\
\hline
\end{tabular}

\subsection{Al fin y al cabo}

Con este reformulador, de reconsideración presentada como definitiva, el locutor toma en cuenta una o varias perspectivas del miembro anterior para exponer una opinión como un compendio cuya fuerza argumentativa es mayor que la de los miembros precedentes. De manera similar se define en el Diccionario de partículas (DP, Santos Río 2003). El DCOE (Fuentes Rodríguez 2009) distingue tres funciones de al fin y al cabo: como conector puede ser justificativo y recapitulativo de reconsideración y como operador es argumentativo. Martín Zorraquino y Portolés Lázaro (1999: 4139) también lo consideran operador cuando los argumentos anteriores son implícitos. 
En (1) el marcador introduce lo que para el locutor resulta un juicio definitivo, coorientado con los miembros anteriores. Además, le precede un pues consecutivo que refuerza su efecto:

(1) [...] el blanco es la reunión de todos los colores, su ausencia da lugar a otro color que también ciega, el negro. Pues al fin y al cabo, tanto el exceso de blancura como el de negrura terminan igual, ocultándolo todo. (El País. Babelia, 24/04/2004, CREA)

Belo objedinjuje sve boje, njegovo odsustvo ustupa mesto drugoj boji koja takođe zaslepljuje, crnoj. A na kraju krajeva, i višak belog kao i višak crnog konačno sakriju sve.

En el mismo tono de corroboración de los miembros anteriores está el siguiente ejemplo serbio con el marcador uostalom, conmutable con na kraju krajeva, que en el RMS se define como partícula usada "kad se iznosi još neka okolnost saglasna sa smislom već rečenog"2.

(2) [...] za nju je i to spadalo u neshvatljivu veličinu njenog tate da on ne sluša stvarno ono što mu se govori, nego zamišljen gleda negde u daljinu, kroz prozor. Uostalom, on je takav i sa odraslima. (Andrić, I. 1958: 21)

Para ella también esto pertenecía a la grandeza inconcebible de su papá que no escuchaba en realidad lo que le decían, sino que miraba pensativo por la ventana, hacia las lejanías. Al fin y al cabo, él era así también con los adultos.

El marcador al fin y al cabo se combina con los conectores causales, con pero y con $y$ que concuerdan con su significado. Con los primeros, el miembro introducido por el marcador obtiene el sentido de explicación justificativa. Con pero la condensación final tilda de menos importantes las calificaciones anteriores con los adjetivos restrictivos para contraponer con más contundencia la esencia semántica del nombre 'guerra'. Con y se concibe como continuación de serie:

(3) A Olga Knipper la vemos en esta fotografía de la época que aparece en la cubierta del libro ladeando la cabeza que se apoya sobre ambas manos, labios finos, mirada soñadora, expresión sensible; es una

\footnotetext{
${ }_{2}^{2}$..cuando se expresa una circunstancia más, que está en consonancia con el sentido de lo ya dicho.
} 
pose de estudio, artificial, representándose a sí misma, porque al fin y al cabo es actriz. (ABC Cultural, 30/08/1996, CREA)

Na ovoj fotografiji iz tog doba vidimo Olgu Kniper na koricama knjige, nakrenute glave oslonjene na obe ruke, tankih usana, sanjalačkog pogleda, s izrazom nežnosti; to je poza u studiju, veštačka, na kojoj predstavlja samu sebe, jer je uostalom/na kraju krajeva glumica.

(4) De esta forma se nos presenta un drama familiar tipo. Un hijo en un frente, otro en el propio, un hermano en el otro bando... Guerra civil, guerra cruel, guerra fratricida, pero al fin y al cabo guerra (Odiseo Revista de Historia, № 1, 22/04/2001, CREA)

Na taj način dobijamo tipsku porodičnu dramu. Jedan sin na jednom frontu, drugi na svom, jedan brat na drugoj strani... Građanski rat, okrutan rat, bratoubilački rat, ali na kraju krajeva rat.

(5) Ima puno razloga da se postavi sledeće pitanje: Koji je današnji razlog da Amerika ignoriše prava Srba na Kosovu, u BiH, u Hrvatskoj i na kraju krajeva u Srbiji? (SrpCorp2013, ej. no 20)

Hay muchas razones para hacer la siguiente pregunta: ¿Cuál es la razón actual por la que América ignora los derechos de los serbios en Kosovo, en Bosnia y Herzegovina, en Croacia, y al fin y al cabo en Serbia?

El (6) termina con un argumento decisivo del locutor y solo a partir de él se infiere que los miembros anteriores tratan de un tópico diferente. Es el caso en el que al fin y al cabo funciona como operador, ya que modifica su propio miembro discursivo. Siendo el argumento decisivo, indica que hay otros, menos importantes que la herencia, pero que pueden ser relevantes para la grandeza de un reino o un rey.

(6) [...] moje kraljevstvo se prostire na nekih 450 kvadratnih kilometara. Ali to niko ne zna. [...] Nikada nisam mario za velika kraljevstva. Veličina kraljevstva ništa ne doprinosi veličini kralja. Naprotiv. Velika carstva okupljaju svakojaki ološ, a car ima sve mane svojih podanika. Na kraju krajeva, ja svoje kraljevstvo nisam nasledio (SrpCorp2013, ej. no 32)

Mi reino se extiende sobre unos 450 kilómetros cuadrados. Pero nadie lo sabe. Nunca me importaban los reinos grandes. La grandeza de un reino no contribuye nada a la grandeza de su rey. Al contrario. 
Grandes reinos reúnen todo tipo de canallas, y el emperador sufre de todos los defectos de sus súbditos. Al fin y al cabo, iyo no heredé mi reino!

Cuando se trata de la heterorreformulación (la reformulación del interlocutor), se confrontan las posturas de dos locutores. En el diálogo que sigue una mujer intenta justificar la promiscuidad de la hermana de su amiga, mientras que esta discrepa, reconsiderándolo con alegar sus propios argumentos:

(7) - Y hay que ver la vida que lleva, porque ya me dirás si es normal vivir como vive. [...] Y luego, eso de acostarse con el primero que llega, ¿pero qué principios son esos? Te digo que me avergüenzo de ser su hermana.

- Mujer, si le gusta darse un revolcón de vez en cuando... eso lo hacemos todas, la que más y la que menos.

- Sí, pero dentro de un orden, quiero decir que yo estoy casada como Dios manda. Janti también tiene a su marido y tú, al fin y al cabo, vivir con un hombre..., pues no es que esté bien, pero, vamos, es uno. (Hidalgo, I. 1988, Todas hijas de su madre, CREA)

- Da vidiš kakav život vodi, pa mi onda reci je l' normalno da živi k'o što živi. I to da legne s prvim koji naiđe, ma kakvi su to principi? Kažem ti, sramota me je što sam joj sestra.

— Ej bre, pa voli tu i tamo da se kresne... to sve radimo, neka više, neka manje.

- Jeste, ali treba da ima nekog reda, hoću da kažem, ja sam udata kô što Bog zapoveda. Hanti isto ima muža, i ti, uostalom / na kraju krajeva / u krajnjoj liniji živiš sa jednim čovekom..., nije baš da je u redu, al' 'ajde, bar je jedan.

Como se ha podido comprobar, el marcador na kraju krajeva y su sinónimo u krajnjoj liniji tienen el significado correspondiente al español al fin y al cabo.

\subsection{A fin de cuentas}

El reformulador a fin de cuentas (la variante menos frecuente es en fin de cuentas) comunica que antes de introducir la opinión definitiva, había un proceso de reflexión sobre diferentes opciones, explícitas o no. En el $D P$ se presenta como locución adverbial argumentativa y como 
consecutiva y en el DCOE como conector justificativo, equiparado con el mismo valor de al fin y al cabo.

En un trabajo temprano Fuentes Rodríguez (1993) subraya el valor conclusivo del significado de fin, lo que tanto a al fin y al cabo como a a fin de cuentas concede el sentido terminativo, como en al final y después de todo, pero les niega el valor reformulativo, excepto cuando el argumento introducido por el marcador acaba invalidando los argumentos anteriores.

El siguiente fragmento contiene dos ejemplos con dos sentidos diferentes. El primero es justificativo y el más pertinente entre todos los argumentos imaginables, ya que son implícitos. El segundo presenta una afirmación de equivalencia entre otros humanos y nosotros, pero dando a saber que se dejan al margen las posibles objeciones, o argumentos, que podrían contradecirla o modificarla por haber desatendido otros eslabones evolutivos que había en medio:

(8) Gobernaron Europa y Oriente Próximo a su antojo [los Homo heldelbergensis]. A fin de cuentas, eran Homo sapiens. Pero pertenecían a otra humanidad que no era la nuestra o, al menos, no la que nos ha legado su código genético. Los otros humanos - nosotros, a fin de cuentas - aún no habían abandonado África cuando ellos dominaban el Viejo Continente. (Cardeñosa, B. 2001. El código secreto. Los misterios de la evolución humana, CREA)

Vladali su Evropom i Bliskim istokom kako su hteli [Homo heldelbergensis]. Na kraju krajeva, bili su Homo sapiens. Ali pripadali su nekim ljudima koji nisu kao mi, ili bar ne onima koji su nam ostavili svoj genetski kod. Oni drugi ljudi - mi, na kraju krajeva - još ne behu napustili Afriku kada su ovi vladali Starim kontinentom.

Combinado con otros conectores, este marcador obtiene diferentes matices de sentido. Así, en (9) se resalta la continuación de la argumentación y en (10) el nuevo argumento reconsiderado se opone a lo expresado en el miembro anterior como más convincente y objetivo, obteniendo un matiz concesivo, por lo que hay dos posibilidades de traducción:

(9) Aristóteles escribió que "la ética procede de la costumbre". Y, a fin de cuentas, hábitos y costumbres vienen a ser el resultado de los actos, singulares y concretos, con que cada día vamos haciendo nuestra vida. (VV. AA. Filosofía. 1o bachillerato. Anaya. 1998, CREA) 
Aristotel je napisao da "etika potiče iz običaja". I na kraju krajeva, navike i običaji su rezultat postupaka, pojedinačnih i konkretnih, tako da svakog dana polako izgrađujemo svoj život.

(10) Remontémonos al primer sanador, [...] al primer chamán. Él representa el nacimiento del tronco común del que emergen las diferentes ramas del saber; de él derivan las diversas tradiciones médicas, y desde él se desarrollarán los desiguales métodos de saber; uno de ellos, posiblemente el más válido, pero a fin de cuentas, una rama entre varias, no la única, es el de la medicina científica. (Lucena Marotta, F. 2002. Qué significa estar sano, CREA)

Vratimo se prvom vidaru, prvom šamanu. On predstavlja nastanak zajedničkog stabla iz kojeg rastu različite grane znanja; iz njega se izvode razne medicinske tradicije i počev od njega se razvijaju raznorodne metode saznavanja; jedna od njih, možda najvrednija, ali na kraju krajeva/ipak samo jedna od grana, ne jedina, jeste naučna medicina.

El locutor de (11) alega su argumento reconsiderado como una concesión y el de (12) como una razón de mayor importancia:

(11) Mira tu expediente. Es un expediente bastante cargadito. Realmente, no entiendo cómo te han caído tan pocos años, aunque, a fin de cuentas, eso no es asunto mío. (Ortiz, L. 1976. Luz de la memoria. CREA)

Pogledaj svoj dosije. Poprilično krcat dosije. U stvari, ne razumem kako si zaradio tako malo godina, iako, na kraju krajeva, nije to moja stvar.

(12) Luego, nos pasamos toda la tarde, después de la comida de Navidad, haciendo suposiciones sobre qué le habría parecido Yoni a Miguel Conde, a Marita, la mujer de Miguel Conde — con lo estirada que era -, a Marta Conde, que algo tendría que decir, porque a fin de cuentas iba a ser su cuñado... (Mendicutti, E. 1995. Fuego de marzo, CREA)

Zatim smo celo popodne, posle božićnog ručka, nagađali kako se Džoni učinio Migelu Kondeu, Mariti, ženi Migela Kondea — pošto je tako uštogljena -, Marti Konde koja je valjda imala šta da kaže, jer će joj na kraju krajeva postati zet. 
Aunque en serbio seguimos utilizando el mismo marcador, se consiguen los efectos de sentido correspondientes al original español.

\subsection{Al fin y a la postre}

El reformulador al fin y a la postre es de uso restringido. Tiene la variante al fin y al postre, todavía más rara. El DP lo define de forma idéntica como al fin y al cabo y el DCOE como conector justificativo remitiendo a al fin y al cabo. Martín Zorraquino y Portolés Lázaro (1999: 4138, n. 88) mantienen que es un adverbio que, a pesar de su similitud con el marcador anterior, mantiene su significado original de en último término. Por todo lo dicho, en esta ocasión no lo analizamos, sino que apuntamos que en la traducción al serbio le corresponden los mismos dos marcadores que para al fin y al cabo.

\subsection{En resumidas cuentas}

Este marcador es de un semantismo muy transparente: el miembro que introduce reconsidera lo dicho resumiéndolo en el marco del mismo punto de vista. En el $D P$ se describe como locución adverbial realizativa de reformulación y en el $D C O E$ como conector conclusivo. Lo que diferencia este reformulador de otros semejantes como en resumen, en síntesis, en suma y en conclusión, es que sus miembros pueden estar antiorientados (Portolés 2011: 110-111). Se traduce con u kratkim crtama, ukratko rečeno.

Aquí (13), después de los elementos que versan sobre el mismo tópico, coorientados y explícitos, se llega a una reformulación sintetizada sobre el tema:

(13) Las letras de las canciones de Javier Krahe han sido reivindicadas por más de una generación musical, dado el rigor de sus rimas matemáticamente perfectas, los juegos de palabras que contienen $\mathrm{y}$, en resumidas cuentas, el genio compositor que siempre vierte en ellas. (El Mundo, 30/10/1996, CREA)

Tekstove pesama H. Krahea uzimalo je više muzičkih generacija zbog strogo i matematički savršenih rima, igara reči u njima i, $\underline{u}$ kratkim crtama, kompozitorskog nadahnuća koje nikad nije izostajalo.

En el siguiente ejemplo, tras unas reflexiones no relacionadas con el personaje de Flora, la locutora cambia el tema, pero sin razonarlo, 
exponiendo de manera concisa y en forma interrogativa la reformulación de todos los elementos implícitos. Lo traducimos con ukratko (rečeno), brevemente dicho, que encontramos más apropiado para introducir una pregunta, dado que después de u kratkim crtama es preferible un miembro asertivo:

(14) Pero ahora debo centrarme en Flora. Con serenidad, con justicia. Porque, en resumidas cuentas, ¿tenía algo de raro la aparición de Flora aquella misma tarde en el hotel? (Fernández Cubas, C. 1994, Con Ágatha en Estambul, CREA)

Ali sada moram da se usredsredim na [2001] Floru. Spokojno, pravedno. Jer, ukratko (rečeno), je li bilo nečeg čudnog u tome što se Flora tog istog popodneva pojavila u hotelu?

El (15) tiene los argumentos antiorientados:

(15) Mnogi od njih su puno šta obećavali, ali od njih pomoći nisam dobio. Ukratko rečeno, retki su pojedinci koji su shvatili naše teškoće i potrebe i pomogli nam. (SrpCorp2013, ej. no 31)

Muchos de ellos prometían muchas cosas, pero de ellos no recibí ayuda. En resumidas cuentas, son raras las personas que comprendieron nuestras dificultades y necesidades y nos ayudaron.

Para resumir, el marcador tratado funciona de manera bastante parecida en las dos lenguas, salvo que en serbio hemos detectado una sensibilidad respecto al tipo de acto de habla, así que para las reformulaciones interrogativas es preferible ukratko (rečeno).

\subsection{En definitiva}

El último del subgrupo de reformuladores de reconsideración definitiva es el representante por antonomasia: en definitiva. Instruye la intención comunicativa de presentar una nueva perspectiva como final. El $D P$ remite al adverbio enunciativo definitivamente, del que como de una variante hablan Martín Zorraquino y Portolés (1999: 4135, n. 86), igual que la función de operador en el caso del miembro anterior implícito. En la misma línea, el DCOE distingue un en definitiva conector conclusivo y otro operador enunciativo. Fuentes Rodríguez (1993: 186) menciona la jerarquía dentro de la cual el argumento más fuerte es el introducido 
por el marcador. Asimismo observa que, cuando se trata del sentido de conclusión, en definitiva y definitivamente no son conmutables, como en (16). Al sentido conclusivo, Herrero Ingelmo (2013: 7) añade los de sobre todo, fundamentalmente, finalmente y por lo tanto.

El autor de (16) envía el mensaje (conclusión) de que en la escala de importancia el pueblo está más alto que la lengua. Hay dos opciones de traducción, dakle y stoga (por lo tanto); pa equivale a y continuativo.

(16) En este ambiente intelectual, muchos de los estudiosos por lo que se preocupaban en realidad era por los orígenes de su propia lengua y en definitiva de su propio pueblo. (Villar. F. 1996. Los indoeuropeosy los orígenes de Europa, 20)

\# Se preocupaban por los orígenes de su lengua y definitivamente de su pueblo.

U takvoj intelektualnoj sredini, mnogi naučnici su u stvari bili zaokupljeni poreklom sopstvenog jezika, pa dakle/pa stoga i sopstvenog naroda.

En el discurso oral en definitiva puede encabezar su propio turno de palabra preguntando por la conclusión, por lo que tampoco se puede sustituir con el adverbio. En serbio ocurre lo mismo con dakle:

(17) A

B. ¿En definitiva? (Resume, por favor, dime la conclusión.)

(Fuentes Rodríguez 1993: 186)

A.

B. Dakle? (Sažmi, zaključi)

Rajić (2013) trató con detalle las múltiples funciones de dakle en serbio, entre ellas la consecutiva, así como sus correspondencias en español; con el (18) añadimos una más, en definitiva. Además, es un ejemplo de argumenos antiorientados:

(18) Sospecho ahora, incómodo, que este ritmo vodevilesco no es quizá el más apropiado para contar lo que en definitiva me proponía contar... (Marsé, J. 1978. La muchacha de las bragas de oro. CREA)

Sada s nelagodom podozrevam da taj vodviljski ritam možda nije najprikladniji da ispričam to što sam, dakle, naumio da ispričam. 
Finalmente, en el (19) se trata de tópicos diferentes:

(19) El hecho me desconcertó y hasta me supo mal: quizás alguno de los presentes conocía este íntimo distintivo físico. En definitiva, ni ella ni yo salíamos propiamente perjudicados... (Goytisolo, L. 1984. Estela del fuego que se aleja. CREA)

Događaj me je pomeo, čak sam se osetio loše: možda je neko od prisutnih znao za tu intimnu fizičku odliku. Najzad, ni njoj ni meni to nije nanosilo nikakvu štetu.

Como resulta, no hay una correspondencia exacta, o por lo menos preferente, entre en definitiva y un marcador serbio, así que, como siempre en estos casos, hay que captar con cuidado todas las instrucciones contextuales para detectar el efecto de sentido correcto y no falsear la intención original.

\subsection{Después de todo}

El matiz definitivo de los marcadores que hemos analizado hasta este punto es el que los diferencia del reformulador después de todo, con el que el acento recae en una formulación nueva, opuesta a la de los miembros anteriores, explícitos o implícitos. El DP de nuevo ofrece una definición de locución argumentativa causal explicativa, y el $D C O E$ la de conector justificativo.

En ausencia de argumentos abiertamente expresados, después de todo se convierte en un operador, así que el interlocutor infiere por su cuenta los argumentos que le preceden.

En la traducción al serbio acudimos a un marcador poco lexicalizado por lo que hay que prestar especial atención al contexto para no confundir el valor discursivo con el oracional y fallar en la elección. Una relativa proximidad de significado con na kraju krajeva es indicador de que se trata de un marcador. En este sentido el siguiente ejemplo es hasta cierto punto ambiguo: creemos que después de todo conserva una parte de su matiz semántico temporal, pero también opera sobre su miembro dejando la posibilidad de establecer una inferencia a partir del elemento cuantificador:

(20) Este hombre - un buen sacerdote- ha vivido y vive profundamente su fe. Todo lo que sabe se reduce a estas tres 
certezas: "Después de todo, Dios es Amor; después de todo, somos amados; después de todo, somos libres". (La Vanguardia, 16/10/1995, CREA).

Ovaj čovek — dobar sveštenik - živeo je i živi duboko u svojoj veri. Sve što zna svodi se na ove tri izvesnosti: „Naposletku, Bog je Ljubav; naposletku, voljeni smo; naposletku, slobodni smo".

El ejemplo (21) en serbio demuestra, sin embargo, que los argumentos antecedentes explícitos disminuyen el grado de ambigüedad. Todos ellos resultan impertinentes para la conclusión de que el estado siempre sale ganando. El último miembro (što bi trebalo izbeći) se justifica y se reafirma con el introducido por el marcador. Además, aquí se da lo que Garcés Gómez (2008: 138) señala como dimensión polémica (aunque no sea dialógica):

(21) Ustav zabranjuje upotrebu neautorizovanih traka i sud ih ne prihvata kao dokaz. Stoga ostaje otvoreno pitanje kako novine mogu da se ponašaju kao paralelna pravda koristeći kao podlogu takve izvore. U tom kontekstu navodi se podatak o konstantnoj upotrebi medija u službi političkih i ekonomskih interesa, što bi trebalo izbeći. Država, posle svega, ukazuje se, ispliva kao pobednik, pa i po cenu ilegalnih akata. (SrpCorp2013, ej. no 88)

La Constitución prohíbe la utilización de cintas no autorizadas y los juzgados no las aceptan como prueba. Por esto queda abierta la cuestión de por qué los periódicos pueden actuar como justicia paralela basándose en estas fuentes. En este contexto se cita el dato de un uso constante de los medios al servicio de los intereses políticos y económicos, lo cual debería evitarse. El estado, después de todo, se señala, sale como vencedor, incluso a costa de documentos ilegales.

La oposición que se crea entre los argumentos del segmento que le precede y el introducido por el marcador, que presenta una perspectiva contraria, a veces puede obtener una lectura concesiva favorecida por el entorno contextual. En estos casos en serbio se puede utilizar el conector contraargumentativo ipak:

(22) La realidad, por mucho que se la tuerza, disfrace y falsee mediante el juego de palabras engañosas, obedece en último término a sus propias leyes. Y así vemos que, a trancas y barrancas, las cosas marchan adelante y, después de todo, no van saliendo tan mal. (El País, 30/12/1980, CREA) 
Stvarnost, koliko god da se iskrivljuje, prerušava ili izvrće igrom varljivih reči, u krajnjoj liniji se povinuje svojim sopstvenim zakonima. Pa tako vidimo da stvari, preko staza i bogaza, idu napred i da ipak (najzad) ne ispadaju tako loše.

En el siguiente ejemplo los diferentes tópicos y la antiorientación argumentativa han sido utilizados para conseguir un fuerte efecto de ironía. Aparte de esto, el matiz consecutivo posibilita la traducción najzad que se diferencia de posle svega precisamente por este ingrediente semántico potenciado con la conjunción $y$, que aquí, a pesar de la contrariedad, no se traducirá con $a$ (y contrastiva):

(23) Quisiera pedir a estos señores que no sean tan considerados con nuestros impuestos y hagan una excepción enchufando a sus niños para que disfruten de las ventajas que les ofrecen en un centro municipal de Cercedilla, donde podrán, totalmente gratis, envenenarse. No hay prisas. Pueden entrar en cualquier turno. Veneno siempre queda y, después de todo, sus niños, aunque hijos de ministros, alcaldes o directores generales de Sanidad, también tienen derecho a unos días en Cercedilla con veneno incluido, ¿ ${ }^{\circ}$ no? (El País, 01/08/1986, CREA)

Želela bih da zamolim tu gospodu da ne budu toliko uviđavni sa našim porezima, pa da naprave izuzetak i preko veze ubace svoju decu da uživaju u prednostima koje nudi opštinski centar u Sersedilji u kome će potpuno besplatno moći da se otruju. Bez žurbe. Mogu da se prijave za bilo koju smenu. Otrova uvek ima, i najzad, njihova deca, iako deca ministara, gradonačelnika ili generalnih direktora u zdravstvu, takođe imaju pravo na nekoliko dana u Sersedilji sa uključenim otrovom, zar ne?

De lo expuesto sigue que con el marcador después de todo en serbio hay que estar atento a los sentidos derivados de los contextos particulares, puesto que le corresponden tres opciones de traducción: con posle svega y najzad como más apropiadas, y con ipak en los casos de inferencias concesivas.

\subsection{Total}

Como el anterior de su subgrupo, el marcador total reconsidera las opciones explícitas o implícitas para ofrecer una nueva perspectiva global, que corresponde a su semántica. El DP lo etiqueta de adverbio 
reformulativo con tres significados: uno sinónimo de en suma, en resumen, en resumidas cuentas y en conclusión, otro de así (que) y el tercero de después de todo y al fin y al cabo. Todo esto indica un abanico de posibles efectos de sentido. El DCOE distingue entre total conector conclusivo y conector justificativo. Martín Zorraquino y Portolés (1999: 4137-4138) observan que es más frecuente en el discurso oral y, por otro lado, que como recapitulativo es básicamente conclusivo, mientras que como operador refuerza su miembro discursivo.

La variante en total se considera anómala.

En serbio le corresponde sve u svemu. Aquí (24) se presenta una función prototípica de este marcador. Le preceden varios argumentos, todos coorientados, que se engloban y a partir de ellos se saca una nueva conclusión:

(24) [...] desde la semana siguiente a la separación no habían dejado de verse ni de comer juntos en restaurantes caros a los que no se les había ocurrido llevarme nunca. También iban al cine con frecuencia, y al teatro, y más de un fin de semana se habían escapado a París, como dos jóvenes alocados, viviendo un romance improcedente a todas luces. Total, que mientras yo regaba las plantas de ella y cultivaba las manías de él [...], ellos llevaban la vida que me correspondía a mí. (El País, 18/09/1998)

Od sedmice koja je usledila razvodu stalno su se viđali i odlazili na ručak u skupe restorane u koje im nikad nije palo na pamet da me pozovu. Išli su i u bisokop, i u pozorište, a nekoliko puta su za vikend skoknuli do Pariza, kao dvoje mladih i otkačenih koji proživljavaju očigledno neprimerenu romansu. Sve u svemu, dok sam ja zalivao njeno cveće i pazio na njegove manije, oni su živeli životom kojim je trebalo da živim ja.

El siguiente diálogo demuestra que la conclusión puede sacarla el interlocutor basándose en los argumentos del locutor y que tal conclusión, además, contiene un argumento antiorientado:

(25) HASANAGA: Šta misliš?

JUSUF: Mislim da pristaneš.

HASANAGA: Da nije sumnjivo? Ne bi on ovo na prezent zbog sitnice... Pogledaj, dobri su. Laže da je dvesta dukata. Al nek je i sto, pa je one mnogo. Kako ti ocenjuješ situaciju?

JUSUF: Ovo ti je dobra prilika, istina, možda malo neprijatna, ali, sve u svemu, vrlo pogodna... (SrpCorp2013, ej. no 97) 
HASANAGA: ¿Qué te parece?

JUSUF: Pienso que puedes aceptar.

HASANAGA: ¿No te parece sospechoso? No lo regalaría él por poca cosa... Mira, son buenos. Miente que valen doscientos ducados. Pero aunque valgan cien, es mucho. ¿Cómo ves tú esta situación?

JUSUF: Es una buena ocasión, eso sí, un poco incómoda, pero, total, muy favorable...

Este marcador también puede introducir un miembro con un argumento implícito; como no lo conocemos (aunque lo supongamos), en serbio ya no se puede utilizar sve u svemu sino ionako que marca la diferencia con lo desconocido. Este adverbio sirve como un reformulador que engloba lo no explícito gracias al elemento deíctico que contiene:

(26) En algún lugar de mi cabeza, lo suficientemente lejos como para no molestar, lo suficientemente cerca como para hacerse notar, palpitaban mi minoría de edad, seis años todavía para los veintiuno (la mayoría de edad estaba entonces en los veintiuno, a mí me daba igual, total no votaba nadie), el drama del pantano... (Grandes, A. 1989. Las edades de Lulú, CREA)

U nekom kutku glave, dovoljno daleko da ne smeta, dovoljno blizu da se oseća, pulsirali su mi maloletstvo, još šest godina do dvadeset prve (punoletstvo je tad bilo u dvadeset prvoj, meni je bilo svejedno, ionako niko nije glasao), drama na jezeru...

Mancera Rueda (2008: 364) observa que en las columnas periodísticas total sirve para reanudar el tema después de una digresión. En estos casos, en serbio se utilizaría el marcador elem, propio del lenguaje menos formal (Čudomirović 2009), aunque, creemos, apto para el lenguaje periodístico. Otra opción es dakle que, como conclusivo, en un contexto dado puede obtener el efecto de sentido de resumen, derivando en algo como un salto de vuelta al principio:

(27) Pero nada existe hasta que lo bautizan. Y el genio popular ha dado con un mote para denominar a sus nuevos amos, gobernantes, mandamases, o figurantes, que de todo tienen. La fórmula lingüística ha tomado, además, a don Alfonso como fuente de inspiración, quizá porque el que más presumía de austeridad dio pruebas, en aquel atasco famoso, de singular prepotencia, propia de nuevo señorito. Total, que a los nuevos instalados, a los que han subido de clase, a los que no han cambiado de chaqueta, sino pasado del almacén al sastre, han dado en bautizarlos la mystère set. ( $A B C, 10 / 07 / 1988$, CREA) 
Ali ništa ne postoji dok ga ne krste. I narodni duh je smislio nadimak za nove gospodare, vladare, glavešine ili statiste, jer su pomalo sve to. Jezička formula je, osim toga, crpla nadahnuće od don Alfonsa, možda zato što je onaj ko se najviše busao odmerenošću, u onoj čuvenoj saobraćajnoj gužvi pružio dokaze izuzetne prepotencije svojstvene novopečenoj gospodi. Elem/Dakle, nove nameštenike, koji su se izdigli za klasu, koji nisu prevrnuli ćurak nego su od magacionera postali krojači, prozvali su mystère set.

Resumiendo, en su uso prototípico total se corresponde con sve u svemu. Sin embargo, cuando le preceden argumentos implícitos, se traducirá con ionako que señaliza lo que se interpreta como diferente por desconocido y, finalmente, cuando retoma el tema después de una digresión, se usará elem o dakle.

\section{Conclusiones}

Analizando el subconjunto de los reformuladores de reconsideración y su polifuncionalidad pragmática, llegamos a la conclusión de que la reformulación a) es ostensiva, b) está destinada a la consecución de un determinado efecto en el receptor y contribuye a una mejor comunicación, c) contribuye a la coherencia del discurso y d) aclara, modifica y añade nuevo material, por lo que está plenamente justificada desde la perspectiva informativa.

La distinción entre significado y sentido y los diferentes grados de su contenido conceptual o procedimental, demuestra que los marcadores de reformulación definitiva y los de la nueva, tanto en español como en serbio, no están plenamente gramaticalizados.

Los tres reformuladores en español que contienen el lexema fin, "al fin y al cabo", "a fin de cuentas" y "al fin y a la postre", en serbio se corresponden con los reformuladores que también se relacionan con el lexema kraj: "na kraju krajeva" i "u krajnjoj liniji"; con el matiz conclusivo-justificativo ambos son conmutables con uostalom, lo que no es el caso si se combinan con pero, cuando su sentido concesivo puede ser reforzado con "ipak". El marcador "en resumidas cuentas" equivale en serbio a "u kratkim crtama", "ukratko (rečeno)", mientras que "en definitiva" con el sentido conclusivo se traduce con "dakle" o "stoga", con el sentido consecutivo también con "dakle" y, en el caso de que el tópico del miembro discursivo introducido por este reformulador difiera del anterior, con "najzad". El reformulador "después de todo", que aporta una 
formulación nueva (igual que "total"), cuando tiene el sentido justificativo o consecutivo se corresponde con "najzad" i "posle svega", y con el sentido concesivo con "ipak". Por último, "total" equivale a "sve u svemu", pero si introduce un miembro discursivo con un argumento implícito, se traduce con "ionako" y, si se usa para retomar el tema después de una digresión, con "elem" o "dakle".

\section{BIBLIOGRAFÍA}

Anscombre, Jean-Claude \& Oswald Ducrot. La argumentacićon en la lengua. Madrid: Gredos, [1988] 1994. Impreso.

Bazzanella, Carla (Ed.). Repetition in dialogue. Tübingen: Max Niemayer Verlag, 1996. Print.

Blakemore, Diane. Semantic constraints on relevance. Oxford: Blackwell, 1987. Print.

Borreguero Zuloaga, Margarita. "La traduccción de los marcadores del discurso: valores, funciones, posiciones y otros problemas". Daniel M. Sáez (Ed.). Últimas tendencias en traducción e interpretación, Madrid: Iberoamericana, Frankfurt am Main: Vervuert, 2011: 123-139. Impreso.

Camacho Adarve, Ma Matilde. Análisis del discurso y repetición: plabras, actitudes y sentimientos. Madrid: Arco / Libros (Oralia. Anejos 5), 2009. Impreso.

Cuenca Ordiñana, Ma Josep \& Carme Bach Martorell. "Contrasting the form and use of reformulation markers". Discourse Studies, Vol. 9, No. 2 (2007): 149-175. Print.

Čudomirović, Jovan. „Rečce kao tekstualni konektori u savremenom srpskom jeziku". Književnost i jezik, LVI/3-4, 2009: 277-295. Štampano.

Fløttum, Kjersti. "A propos de c'est-a-dire et ses correspondences norvégiens". Cahiers de Linguistique Française, 15 (1994): 109130. Imprimé.

Fuentes Rodríguez, Catalina. “Conclusivos y reformulativos". Verba, 20 (1993): 171-198. Impreso.

Fuentes Rodríguez, Catalina. Diccionario de conectores y operadores del español (DCOE). Madrid: Arco / Libros: 2009. Impreso.

Garcés Gómez, Mạ Pilar. La organización del discurso: marcadores de ordenación y de reformulación. Madrid: Iberoamericana / Frankfurt am Main: Vervuert, 2008. Impreso. 
Garcés Gómez, Ma Pilar. La reformulación del discurso en español en comparación con otras lenguas: catalán, francés, italiano, inglés, alemán e islandés. Madrid: Universidad Carlos III de Madrid y Boletín Oficial del Estado, 2009. Impreso.

Garcés Gómez, Ma Pilar. 2010. "Marcadores de corrección y rectificación en los textos escritos". Revista de Investigación Lingüística 13 (2010): 87-105. Impreso.

Grice, Herbert Paul. "Utterer's Meaning and Intention". The Philosophical Review, Vol. 78, № 2 (1969): 147-177. Print.

Grice, Herbert Paul. "Logic and Conversation". Peter Cole \& Jerry L. Morgan (Eds.). Syntax and Semantics 3: Speech Acts. New York: Academic Press, 1975: 41-58. Print.

Gülich, Elisabeth \& Thomas Kotschi. "Les marquers de reformulation paraphrastique". Cahiers de Linguistique Française, 5 (1983): 305-351. Imprimé.

Herrero Ingelmo, José Luis. "Reformuladores de recapitulación: de complementos de modo a marcadores del discuro (en resumen, en síntesis, en suma, en conclusión, en definitiva)", 2013. Web. 10 Ago. 2018.

Mancera Rueda, Ana. "La reformulación en el discurso periodístico: una muestra de la oralidad fingida". Oralia, 11 (2008): 353-374. Impreso.

Martín Zorraquino, Mํㅡ Antonia \& José Portolé Lázaro. “Los marcadores del discurso". Ignacio Bosque \& Violeta Demonte (Eds.), Gramática descriptiva de la lengua española (GDLE). Madrid: Espasa, 1999: 4051-4213. Impreso.

Matematički fakultet Univerziteta u Beogradu. Korpus savremenog srpskog jezika SrpKor2013. Web. Ago-Sep. 2018.

Matica srpska. Rečnik srpskog jezika (RMS). Novi Sad, 2007. Štampano.

Portolés, Jose. "Los marcadores del discurso y la estructura informativa". Óscar Loureda Lamas \& Esperanza Acín Villa (Coords.). Los estudios sobre marcadores del discurso en español, hoy, Madrid: Arco/Libros. 2010: 281-325. Impreso.

Portolés, José. Marcadores del discurso. Madrid: Ariel, 2011. Impreso.

Rajić, Jelena. „Semantika i pragmatika diskursne partikule dakle i njeni prevodni ekvivalenti u španskom jeziku“. Srpski jezik XVIII (2013): 497-512. Štampano.

Real Academia Española. Corpus de Referencia del Español Actual (CREA). Web. Ago-Sep. 2008.

Real Academia Española. Diccionario de la lengua española, 23aㅗ ed. 
Madrid: Espasa, 2014. Impreso.

Rossari, Corinne. "Projet pour une typologie des opérations de reformulation". Cahiers de linguistique française, 11 (1990): 345359. Imprimé.

Rossari, Corinne. Les opérations de réformulation. Berne / Berlin / Francfort s. Main / N. York / Paris: Peter Lang, 1994. Imprimé.

Santos Río, Luis. Diccionario de partículas (DP). Salamanca: Luso-Española de Ediciones, 2003. Impreso.

Sperber, Dan \& Deirdre Wilson. Relevance. Communication and Cognition. Oxford: Basil Blackwell, 1986. Print.

Wilson, Deirdre \& Dan Sperber. "Linguistic form and relevance". Lingua, 90, 1/2 (1993): 1-25. Print.

\section{DISCOURSE MARKERS OF RECONSIDERATION}

\section{Summary}

Within Pragmatics and from the very beginning of the discipline, discourse markers have always raised special interest as one of the factors in discourse coherence largely due to the key role they play both in the processing of information and in the transmission of speaker's communicative intention. The study of these elements has yielded important results especially in Hispanic Studies. For this reason, and supporting our research on the theories developed by Hispanic Studies scholars, we have chosen the class of reformulators of reconsideration in order to subject them to contrastive analysis with the Serbian ones. Within the group of reformulators of reconsideration we can distinguish two subgroups: markers that introduce a new reformulation (total, después de todo) and the subgroup of markers introducing a definitive reformulation (al fin $y$ al cabo, a fin de cuentas, en definitiva, etc.). Bearing in mind that all reformulation establish a certain type of repetition, our aim is to examine in what way and by means of what linguistic media this relation is established. Once this is established, the next step is to detect their correspondents in Serbian. The results will be relevant especially to two areas of applied linguistics: Teaching Spanish and Serbian as foreign languages and in Translation.

Keywords: discourse marker, reformulation, reconsideration. 